\title{
TORSION OF THE THIRD OMENTUM
}

\author{
By A. L. Black, F.R.C.S. \\ Senior Surgical Registrar, Liverpool United Hospitals; David Lewis Northern Hospital
}

A careful search of the literature reveals only two previous reports of torsion of the third omentum; the first by Von Klimko in 1929 and the second by Erdély in 1932. The first recognition of a "Third Omentum' as an anatomical structure was made by Bierman and Jones in 1923 , who recorded two examples. The first was an accidental finding during laparotomy in a young man suffering from chronic appendicitis, and the second also in a male patient during an exploratory operation to discover the cause of a filling defect in the pyloric region in a stomach revealed by $\mathrm{X}$-ray. They found a veil of omentum hanging in front of the anterior surface of the stomach and attached to the lesser curvature of the stomach. They postulated that this " Third Omentum' was of developmental origin due to the persistence into adult life of a fold caused by the ' out pouching' of the lesser omentum which is very occasionally seen in the human embryo. This view has been confirmed by several authors although the anatomical anomaly is rather rare.

\section{Case Report}

The patient was a schoolboy aged 14 years, of rather tall and slim build, who was admitted to the David Lewis Northern Hospital, Liverpool, on the evening of January 8, 1954, suffering from acute abdominal pain. He had no serious illnesses in the past. Some thirty hours before admission, after a moderately heavy meal, the patient experienced a moderately severe pain in the upper abdomen, which recurred at intervals during the rest of that day. There was no vomiting but occasional nausea was experienced. He slept fairly well that night but on rising the next morning he had severe upper abdominal pain which doubled him up and caused him to return to bed. He was restricted to a fluid diet but with each movement, especially turning over in bed, the pain returned though it was relieved by lying quite still. During the day he felt sick at times but did not vomit. There were no urinary symptoms and the bowels were regular.

On examination the patient was lying supine and did not look ill when resting quietly in bed.
The temperature was $99^{\circ} \mathrm{F}$. and the pulse $112 / \mathrm{min}$. (an hour previous when seen in his own home the temperature was $100.2^{\circ} \mathrm{F}$. and the pulse rate $100 / \mathrm{min}$.). There was no jaundice. His tongue had a slight yellowish coating and there was some foetor in the breath. The abdomen moved easily and normally. There was localized tenderness and slight resistance in the region of the right upper rectus. Rectal examination showed no abnormality. The genitalia and hernial orifices were normal. A physician examined the chest and stated that there was no supradiaphragmatic cause for the pain. A specimen of blood was sent for a white cell count and the urine was examined for bile salts.

In the differential diagnosis pleurisy, pneumonia, hepatitis, cholecystitis, peptic ulcer, mesenteric adenitis and appendicitis were considered. All the signs pointed to a lesion below the diaphragm. Cholecystitis and peptic ulceration were thought unlikely to be the cause as the history and age of the patient were rather against these conditions. The history and signs did not suggest infective hepatitis. A tentative diagnosis was made of inflammation in an abnormal highly placed appendix. The white cell count of 20,000 leant support to this diagnosis. Chest $\mathrm{X}$-ray was negative and a straight abdomen $\mathrm{X}$-ray revealed calcified glands in the lower abdomen well below the site of tenderness.

Operation. On opening the abdomen through a right paramedian incision centred on the umbilicus, a moderate amount of slightly blood stained fluid escaped. Exploration disclosed what appeared to be a localized thrombosis or infarct in the lesser omentum ( $2 \frac{1}{2}$ in. by 2 in.). This proved to be an unusual process of omentum which had undergone torsion. Its base was attached to the lesser curvature of the stomach, commencing $\frac{1}{2}$ in. to the left of the pylorus and extending for $\mathrm{I} \frac{1}{2}$ in. along the lesser curvature. This omentum at first appeared to be adherent to the anterior wall of the stomach but was easily separated from it. Both the stomach in this region and the lesser omentum were quite oedematous. The pedicle was transfixed and the twisted omentum was excised. Calcified glands were noted in the root of the mesentery, and before 
closing the abdomen the appendix was removed although it did not appear pathological.

The specimen consisted of a dark plum-coloured lump of fatty omentum about the size of a Victoria plum, attached to a pedicle $\frac{1}{2}$ in. in diameter which had twisted three and a half times in a clockwise direction.

The post-operative course was uneventful, the patient leaving hospital on the twelfth day after operation.

The main interest of this case is that it draws attention to a rare anatomical structure. The clinical features apart from the site of the tenderness and pain do not differ from those of torsion of the commoner omental processes. As in this case, the two previously reported cases were diagnosed $\mathbb{8}$ as acute appendicitis, the correct diagnosis being $c$ made at laparotomy.

I wish to express my thanks to Mr. Philip Hawe for permission to report this case, and to Mr. R. Kellner, one of our medical students, for his most 흘 excellent translation of the articles, in German, to which I have referred.

\section{BIBLIOGRAPHY}

BIERMAN, M. J., and JONES, W. M. (1923), Surg. Gynae. Obst., 36, 708 .

VON KLIMKO, DEZSO (1929), Arch. F. Klin. Chirurgie, 155, 685. ERDLEY, JULIUS (1932), Zentral f. Chirurgie, 3, 2932.

\section{'LETHIDRONE' (NEONATAL) INJECTION}

Burroughs Wellcome \& Co: announce the issue of 'Lethidrone' brand (Neonatal) Injection of Nalorphine Hydrobromide. This product, which contains I $\mathrm{mg}$. of nalorphine hydrobromide, per c.c., is intended for injection into the umbilica vein of the newborn to counteract the depressant effects of obstetric analgesics of a morphine-like nature, such as pethidine, to which it has a specific antagonism. It thus enables more adequate analgesia to be maintained to a later stage in labour without increased risk to the infant. 'Lethidrone' (Neonatal) Injection is available in rubber-capped bottles of 5 c.c.

\section{'LERGINE'}

Burroughs Wellcome \& Co. announce the issue of 'Lergine' brand Tricyclamol Chloride, a new anticholinergic agent which markedly reduces motility of the gastro-intestinal tract and diminishes gastric secretion. The principal indications are as an adjunct to the medical treatment of peptic ulcer and for the relief of spastic conditions of the intestine. 'Lergine' is issued as $50 \mathrm{mg}$. compressed products in bottles of 100 , price r7s. $6 \mathrm{~d}$. per bottle, plus 3s. $3 \frac{1}{2} \mathrm{~d}$. purchase tax, subject to the usual discounts, also in bottles of 500 .

\section{'PROBEX'}

John Wyeth and Brother Ltd. have produced new Beef Liver with iron preparation for the treatment of certain forms of refractory hypochromic anaemia. In a short booklet they describe the place for this preparation, known as $\bar{\AA}$ 'Probex,' in the treatment of patients of this type.

\section{BENGER'S NEW IRON PREPARATION}

Benger Laboratories Ltd., who introduced the first intravenous iron preparation to the medical 3 profession, announce a new iron compound, $\delta$ called 'Imferon,' for iron-deficiency anaemias. It was discovered in their laboratories at Holmeso Chapel and is a solution providing the equivalent of $50 \mathrm{mg}$. elemental iron in each millilitre.

Suitable for either intravenous or intramuscular administration, it will be issued in ampoules of $N$ $2 \mathrm{ml}$. in boxes of 10 and 100 and ampoules of $N$ $5 \mathrm{ml}$. in boxes of 5 and 50.

The solution is neutral, isotonic and contains $\omega$ no local anaesthetic; administration is painless. It is stable in the presence of protein and is free? from iron ions. The iron component is freelyon available for haemoglobin synthesis in irondeficiency anaemias. 